First Aid 
Titles of related interest:

G J Ebrahim: Breast Feeding: the Biological Option

G J Ebrahim: Child Care in The Tropics

G J Ebrahim: Child Health in a Changing Environment

G J Ebrahim: Paediatric Practice in Developing Countries

G J Ebrahim: Practical Mother and Child Health in Developing Countries

G J Ebrahim: Care of the Newborn in Developing Countries

G J Ebrahim: Handbook of Tropical Paediatrics

David Morley and Margaret Woodland: See How They Grow

Jean Ritchie: Nutrition and Families

Muriel Skeet: Family Care

Caroline Uddoh: Nutrition

David Werner: Where There Is No Doctor 


\section{First Aid}

For Community Health Workers in Developing Countries

MURIEL SKEET 
(C) Muriel Skeet 1984

All rights reserved. No part of this publication may be reproduced or transmitted, in any form or by any means, without permission

First published 1984 by

THE MACMILLAN PRESS LTD

London and Basingstoke

Companies and representatives

throughout the world

ISBN 978-0-333-36385-0

ISBN 978-1-349-07067-1 (eBook)

DOI 10.1007/978-1-349-07067-1 


\section{Contents}

Preface

Acknowledgements

Introduction

1 What to Find Out and What to Look For when Someone has an Accident or Becomes Ill Suddenly

2 What to Do when Someone Cannot Breathe Properly: Respiratory (breathing) and cardiac (heart) emergencies

3 What to Do when Someone has a Bad Cut or Wound

4 What to Do when Someone is Burned or Scalded

5 What to Do when Someone Cannot be Woken Up

6 What to Do when Someone Swallows Poison or is Poisoned by a Sting or Bite

7 What to Do when Someone has a Belly Pain (Stomach Ache)

8 What to Do when a Pregnant Woman Becomes Ill: Avoiding illness during pregnancy

9 What to Do when a Pregnant Woman Goes into Labour

10 What to Do when Someone has a Fit

11 What to Do when Someone is Affected by Great Heat or Cold

12 What to Do when Someone Breaks a Bone

13 What to Do when Something is Wrong with the Eye, the Ear, the Nose, or the Mouth

14 How to Take a Patient to Medical Help

Appendix I: How to Prevent Accidents and Poisonings

Appendix II: How to Use some of the Medicines Mentioned in this Book

Appendix III: How to Teach what is in this Book: Addresses from which Teaching Materials can be Obtained 


\section{Preface}

Community health care addresses the main health problems in the community, providing promotive, preventive, curative and rehabilitative services accordingly. By its very nature, therefore, community health care includes the prevention of accidents as well as the prevention of disease; it includes the speedy healing of wounded flesh and broken bones as well as the cure of illness; and it includes the prevention of death and disability from accidents as well as the prevention of those consequences from malnutrition and infections.

In recent years much discussion has taken place of many important issues involved in attaining 'Health for All by the Year 2000'. From these have risen questions concerning vital debatable points such as the kind of basic training members of the health team should receive and how to incorporate individuals and families into that team so that they can become full partners in their own health and welfare development. The knowledge and skills inherent in preventing accidents and carrying out emergency procedures have been recognised as essential components of the former and important contributions to the latter.

All countries of the world have members of their population of all ages who are crippled or deformed for life as a result of accidents on the road, in the home or at work or school. Many old people in our midst are disabled and therefore dependent, because of unfortunate incidents in their earlier lives which could have been either prevented or dealt with more competently when they occurred. And everyone who has worked in a hospital in a developing country will know the horror of admitting to paediatric wards, hundreds of small children who have suffered severe, painful burns because families have not adequately protected the evening fires or boiling cooking pots. Gross and life-long disfigurement and disability or even death are not unusual consequences. Every year in every country of the world, therefore, lives are blighted or lost unnecessarily, just because no one near to hand has known what to do in an emergency.

Many threatened lives can be saved and the quality of saved lives restored-or even improved-if the right treatment is given at the right time, at the right place, by the right persons. This means the carrying out of correct emergency procedures by trained and accessible members of the community at the site of the accident-immediately.

This book is one attempt to help this to happen.

Muriel Skeet

London, July 1983 


\section{Acknowledgements}

I am most grateful to the many people who have made the production of this book possible.

First, to the British Red Cross Society and the League of Red Cross Societies, who, during my years with them, afforded me opportunities to see for myself the outstanding and universal need for the knowledge and skills of First Aid. I am also indebted to them for permission to interpret or paraphrase some of their published and unpublished material.

I acknowledge with very many thanks, permission to adapt some of the text produced by the Division of Health Manpower Development, World Health Organization, Geneva, in The Primary Health Care Worker (Revised Edition), and by David Werner in Where There is No Doctor.
For material I have used in Chapters 1, 2, 3, 4, 12 and 14, I would like to thank Blackwell Scientific Publications (London and Oxford) for their generous permission to reproduce this from Emergency Procedures and First Aid for Nurses, which I edited for them in 1981.

Finally, I thank all nurses, doctors, health educators and others who, over the years, and in many countries of the world, have shared with me their knowledge and experiences in providing first aid and carrying out emergency procedures skilfully and efficiently. To each one I extend my warm thanks and appreciation. 


\section{Introduction}

This book on first aid is written primarily for community health workers in developing countries.

It is assumed that each will have already received some training in primary health care, will understand the most commonly used terms and be able to perform certain curative procedures, such as those included in the revised publication of the World Health Organization, The Primary Health Worker. ${ }^{1}$ It is also assumed that each health worker has access to some form of pharmacopoeia (even if it is only a few sheets of paper), which he can consult for guidance on the dosage and administration of essential drugs.

In some instances the publication itself may be used as a source of reference. Under other circumstances it may be a teaching aid, and the text has been deliberately written in the second person to facilitate its use as an instruction manual. However, because culture, customs, habits, practical taboos and even specific accidents vary from one country to another, it is not possible to write a book which can be used by the whole world without adaptation. It is suggested, therefore, that this publication should be adapted according to local situations, flora, fauna and history. Some examples, such as the use of plants in traditional medicines, are given in the following pages, but there will be many other changes and amendments necessary which only local people will know and can make. Measurements given in the text will also need to be changed to local ones. This is particularly important in relation to medicines and lotions, and also to the making up of fluids such as normal saline or rehydration fluid.

As far as teaching is concerned, again traditional

${ }^{1}$ The Primary Health Worker: Working Guide: Guidelines for Training: Guidelines for Adaptation. WHO, Geneva, 1980 (revised edition). methods should be used: among rural people this is likely to include oral practices. If appropriate, use should be made of story-telling, parables, plays, songs, riddles and local proverbs. Differences in customs, even between next-door villages, are reflected in both the form and content of traditional stories. These should be followed and stories composed to include widely held knowledge, moving on to the action which one hopes to teach. If it conflicts with current beliefs new teaching will simply be ignored or laughed at.

When producing pictures for learning purposes, it may be borne in mind that tests have shown that photographs from which the background has been removed are the easiest for people to assimilate: these are frequently used in successful advertising all over the world. The simple line drawings in this book may also be easily reproduced either on a chalk board or flip chart.

The most important development of any country is the development of its people. People can be a nation's greatest asset and self-help is a key factor in human development. But in order to be self-reliant, knowledge has to be acquired, skills have to be learned and some attitudes have to undergo change. The rural health worker today finds himself with a major responsibility to inform, explain, guide, advise and generally assist his community and all families and individuals in it, to mutual development.

This publication is offered as a small contribution to help him in that important and life-saving responsibility.

M.S. 